Article

\title{
Single-Crystal Growth of Metallic Rare-Earth Tetraborides by the Floating-Zone Technique
}

\author{
Daniel Brunt ${ }^{\dagger}$, Monica Ciomaga Hatnean * ${ }^{*}$, Oleg A. Petrenko, Martin R. Lees ${ }^{\circledR}$ and \\ Geetha Balakrishnan * \\ Department of Physics, University of Warwick, Coventry CV4 7AL, UK; daniel.brunt@npl.co.uk (D.B.); \\ O.Petrenko@warwick.ac.uk (O.A.P.); M.R.Lees@warwick.ac.uk (M.R.L.) \\ * Correspondence: M.Ciomaga-Hatnean@warwick.ac.uk (M.C.H.); G.Balakrishnan@warwick.ac.uk (G.B.) \\ + Current address: National Physical Laboratory, Hampton Road, Teddington TW11 0LW, UK.
}

Received: 27 March 2019; Accepted: 12 April 2019; Published: 19 April 2019

\begin{abstract}
The rare-earth tetraborides are exceptional in that the rare-earth ions are topologically equivalent to the frustrated Shastry-Sutherland lattice. In this paper, we report the growth of large single crystals of $R \mathrm{~B}_{4}$ (where $R=\mathrm{Nd}, \mathrm{Gd} \rightarrow \mathrm{Tm}$, and $\mathrm{Y}$ ) by the floating-zone method, using a high-power xenon arc-lamp furnace. The crystal boules have been characterized and tested for their quality using X-ray diffraction techniques and temperature- and field-dependent magnetization and $\mathrm{AC}$ resistivity measurements.
\end{abstract}

Keywords: crystal growth; floating-zone technique; rare-earth tetraborides; Shastry-Sutherland lattice; frustrated magnet

\section{Introduction}

The inability of a system to minimize the competing magnetic interactions due to crystal structure is termed geometric frustration. This leads to a large ground-state degeneracy, suppressing long-range magnetic order and in many cases gives rise to unusual intermediate magnetic states with a complex arrangement of magnetic moments [1]. The structure of the magnetic ions are generally based around edge- and corner-sharing triangles; some of the most notable examples are the pyrochlore [2], garnet [3] and kagome lattices [4].

One model of a geometrically frustrated magnet is the Shastry-Sutherland lattice (SSL) $[5,6]$, which is an example of a frustrated network with an exact ground-state solution. The SSL only has a handful of experimental realizations, the most notable being $\mathrm{SrCu}_{2}\left(\mathrm{BO}_{3}\right)_{2}[7,8]$, where the $\mathrm{Cu}$ ions form a sublattice that is equivalent to the SSL. This has given a chance to investigate the SSL in the quantum limit [5]. It has been suggested the rare earths in the tetraborides-class of materials can also be described by the SSL [9]. The rare-earth tetraboride-class of materials [10] has attracted a great deal of theoretical and experimental attention, due to the fact that the relatively large magnetic moment of rare-earth ions provides the possibility to investigate the SSL in the classical limit [5].

The rare-earth tetraborides crystallize in a tetragonal structure with space group $P 4 / \mathrm{mbm}$ (127) [11]. The crystallographic structure (shown in Figure 1) can be separated into two parts; a boron and a rare-earth sublattice. The boron sublattice consists of chains of octahedra along the $c$-axis. The octahedra are bonded by pairs of boron atoms in the $a b$-plane, forming rings between the octahedra above and below the rare-earth sites (Figure 1a) [11]. The rare-earth ions form a network of squares and triangles that is topologically equivalent to the SSL $[5,6]$.

Due to the geometrical frustration arising from the arrangement of the magnetic ions in the lattice, the $R B_{4}$ family shows a diverse range of magnetic properties from long-range antiferromagnetic ordering in $\mathrm{ErB}_{4}$ [12] and $\mathrm{GdB}_{4}$ [13] to a wealth of intermediate incommensurate phases observed in 
$\mathrm{NdB}_{4}[14,15], \mathrm{HoB}_{4}[16]$ and $\mathrm{TmB}_{4}$ [17]. One of the most striking features of the family is the presence of fractional magnetization plateaux in magnetic field. The magnetic order in field varies from an up-up-down structure in $\mathrm{HoB}_{4}$ [18] to a complex striped arrangement in $\mathrm{TmB}_{4}$ [19]. A great deal of work has been carried out to understand the origin of these magnetic phases in the context of the SSL. However, recent results have suggested that the SSL alone may not be sufficient to describe the magnetic ordering and that interplanar interactions need to be considered [18].

High-quality single crystals are necessary to investigate the magnetic properties of this interesting class of frustrated magnets. Other members of the boride family of compounds, rare-earth hexaborides, $R \mathrm{~B}_{6}$ [20-22], have been successfully synthesized in single-crystal form using the floating-zone method. The floating-zone technique is ideal to produce pure, high-quality crystals, free from any contamination from fluxes or crucibles. Their large size makes them well suited for magnetic characterization and neutron scattering experiments, crucial to establishing an understanding of the magnetic behavior of $R \mathrm{~B}_{4}$ frustrated magnets.

Single crystals of the rare-earth tetraborides have been produced previously by a variety of methods. Crystals have been prepared by the flux method $[23,24]$ using either $\mathrm{Al}$ or Mo as the flux; however, these crystals are not sufficiently large for investigations involving neutron scattering. Previous studies (see Ref. [24] and references therein) report that $R B_{4}$ (with $R=\mathrm{Y}, \mathrm{Gd} \rightarrow$ Er) melt congruently above $2500{ }^{\circ} \mathrm{C}$, demonstrating that single crystals of these rare-earth tetraborides can therefore be grown by the floating-zone method. This technique has been successfully employed to synthesize crystals of some of the rare-earth tetraboride family, using both RF power $[16,25]$ or optical heating [20,26-28], to reach the high melting temperatures. In the present study, we describe the growth of large single crystals of the majority of the rare-earth tetraborides $R \mathrm{~B}_{4}$ (where $R=\mathrm{Nd}$, $\mathrm{Gd} \rightarrow \mathrm{Tm}$, and $\mathrm{Y}$ ) by the floating-zone technique using high-power xenon arc lamps.
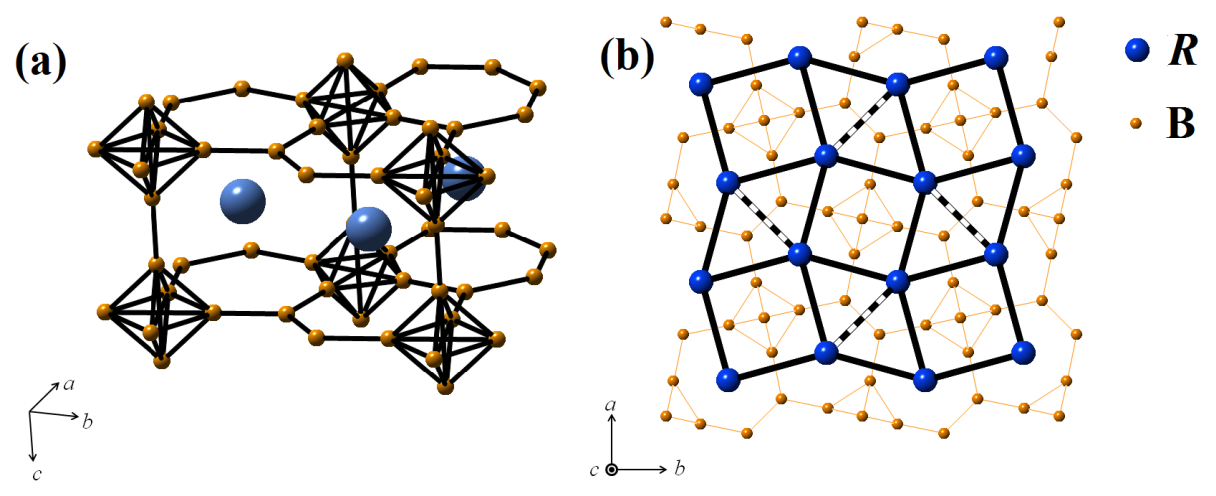

Figure 1. (a) Section of $R \mathrm{~B}_{4}$ lattice to illustrate the $\mathrm{B}_{6}$ octahedra forming chains, as well as the rings above and below the $R^{3+}$ ions. (b) ab plane of $R \mathrm{~B}_{4}$ to illustrate how the SSL maps to the network of squares and triangles formed by the $R^{3+}$ ions.

\section{Methods}

Polycrystalline rods were prepared as described below and single crystals were grown by the floating-zone technique using a four-mirror xenon arc-lamp $(3 \mathrm{~kW})$ optical image furnace (CSI FZ-T-12000-X_VI-VP, Crystal Systems Incorporated, Yamanashi, Japan). The crystal quality was checked using a Photonic-Science X-ray backscattering Laue camera system. Phase purity analysis of the samples was carried out using powder X-ray diffraction on either a Panalytical X-Pert Pro MPD diffractometer (monochromated $\mathrm{Cu} \mathrm{K} \mathrm{K}_{\alpha 1}$ source) or Bruker D5005 diffractometer (monochromated $\mathrm{Cu} \mathrm{K} \mathrm{K}_{\alpha}$ radiation), with a standard Bragg-Brentano geometry. The analysis of the X-ray patterns was performed using the FullProf software suite [29].

Chemical composition analysis was carried out by energy dispersive $X$-ray spectroscopy (EDAX) using a scanning electron microscope on pieces cut from a $\mathrm{NdB}_{4}$ and $\mathrm{TmB}_{4}$ crystal boule. 
A Quantum Design SQUID magnetometer was used to measure the magnetic susceptibility along a principal axis between $1.8<T<300 \mathrm{~K}$ and $0<H<40 \mathrm{kOe}$. AC resistivity measurements were made using the 4-probe method between 1.8 and $300 \mathrm{~K}$ in magnetic fields up to $70 \mathrm{kOe}$ using a Quantum Design Physical Property Measurement System. For all resistivity measurements a current of $10 \mathrm{~mA}$ and a frequency of $113 \mathrm{~Hz}$ was used with the current applied perpendicular to the field direction.

\section{Results}

\subsection{Polycrystalline Synthesis}

In the synthesis of rare-earth borides, it is difficult to avoid the formation and stabilization of small quantities of other $R$-B phases such as $R \mathrm{~B}_{2}, R \mathrm{~B}_{6}, R \mathrm{~B}_{12}, R_{2} \mathrm{~B}_{5}$, as well as $R \mathrm{~B}_{66}$, all of which form at temperatures close to the stabilization temperatures and melting points of the $R \mathrm{~B}_{4}$ [30-36]. Due to the evaporation of boron during the polycrystalline synthesis and crystal growth processes, and the fact that the formation and stabilization of $R-\mathrm{B}$ phases is directly dependent on the $R / \mathrm{B}$ ratio, it is crucial to minimize any changes in stoichiometry. Therefore, throughout the synthesis procedure, care has been taken to compensate for the losses by adding excess boron in the starting compositions.

\subsubsection{Arc Melting}

Samples of $R \mathrm{~B}_{4}$ (with $R=\mathrm{Nd}, \mathrm{Gd} \rightarrow \mathrm{Er}$, and $\mathrm{Y}$ ) were first prepared in polycrystalline form by the arc melting technique. Ingots of rare-earth metal, $R$ (all of $99.9 \%$ purity, supplied by Alfa Aesar or Aldrich), and powdered boron, naturally occurring B (95-97\% purity, purchased from Aldrich) or ${ }^{11} \mathrm{~B}$ (99.52 at\%, purchased from Eagle Picher), were melted together according to the reaction equation:

$$
R+4 \mathrm{~B} \longrightarrow R \mathrm{~B}_{4}
$$

The constituent elements were placed on a water-cooled copper hearth. A 5\% excess of boron was added to account for losses during the melting. The rare-earth piece was embedded in the boron powder to produce a combined mass of approximately $1-2 \mathrm{~g}$. The reaction chamber was evacuated to give a vacuum of $\sim 10^{-2}$ mbar and flushed out with argon gas (3-4 cycles). The melt was then carried out under an argon atmosphere using an arc with a constant current. A molten boule was typically achieved after $30 \mathrm{~s}$ of heating and the arc was kept on the melt for a further $30 \mathrm{~s}$. After each melt the sample was allowed to cool, flipped, and re-melted to improve homogeneity. The resulting arc melted ingots (total of 6-8 g) were then partially crushed and arc melted together in a cylindrical mold to form feed rods (typically 5-7 mm diameter and 35-45 $\mathrm{mm}$ long) for the crystal growth experiments.

\subsubsection{Borothermal Reduction}

Due to the high vapor pressure of thulium, $\mathrm{TmB}_{4}$ could not be prepared by the arc melting method. Polycrystalline $\mathrm{TmB}_{4}$ was prepared by the solid-state synthesis method, according to the borothermal reaction given below:

$$
\mathrm{Tm}_{2} \mathrm{O}_{3}+11 \mathrm{~B} \longrightarrow 2 \mathrm{TmB}_{4}+3 \mathrm{BO} \uparrow .
$$

Powders of the starting oxide material, $\mathrm{Tm}_{2} \mathrm{O}_{3}$ (99.99\% purity, supplied by Alfa Aesar), and boron, naturally occurring $\mathrm{B}$ or ${ }^{11} \mathrm{~B}$, were weighed in stoichiometric amounts, mixed together and heat-treated in a flow of argon gas for several days in a horizontal tube furnace with a vacuum option. The powder mixture was heated at a rate of $150{ }^{\circ} \mathrm{C} / \mathrm{h}$ to temperatures in the range $1400-1500{ }^{\circ} \mathrm{C}$, maintained at these temperatures for $24 \mathrm{~h}$ and then cooled at a rate of $150{ }^{\circ} \mathrm{C} / \mathrm{h}$. 3 or 4 steps were typically necessary to prepare phase pure polycrystalline material. Before starting each step of the synthesis process, the furnace was evacuated to a vacuum of $\sim 10^{-5}$ mbar. The sintered materials were reground between each step to ensure good homogeneity and to facilitate the reaction of the starting materials. The resulting materials were then isostatically pressed into rods (typically $5-7 \mathrm{~mm}$ diameter and 
40-50 mm long) and sintered at $1500{ }^{\circ} \mathrm{C}$ in a flow of argon gas for several hours. The sintered rods were used for the crystal growth.

\subsection{Crystal Growth}

Crystals of all the rare-earth tetraborides were grown by the floating-zone method. The growths were carried out in an argon atmosphere, at pressures in the range 2 to $6 \mathrm{bar}$, and at growth speeds in the range $5-20 \mathrm{~mm} / \mathrm{h}$. Higher gas pressures were used to minimize the loss of volatile elements, such as boron, and elements with high vapor pressure, such as thulium. Initially, polycrystalline rods were used as seeds and once good quality crystals were obtained, a crystal seed was used for subsequent growths. The two rods (feed and seed) were counter-rotated, each at a rate of $15-25 \mathrm{rpm}$. A summary of the conditions used for the different growths of $R B_{4}$ crystal boules is given in Table 1.

Table 1. Summary of the conditions used for the growth of $R B_{4}$ (with $R=\mathrm{Nd}, \mathrm{Gd} \rightarrow \mathrm{Tm}$, and $\mathrm{Y}$ ) crystal boules.

\begin{tabular}{|c|c|c|c|c|}
\hline$R \mathrm{~B}_{4}$ & Growth Rate (mm/h) & Atmosphere & Pressure (bar) & Feed/Seed Rod Rotation Rate (rpm) \\
\hline $\mathrm{NdB}_{4}$ & $15-18$ & Ar & $2-6$ & $15-25$ \\
\hline $\mathrm{GdB}_{4}$ & 18 & Ar & 4 & $15-20$ \\
\hline $\mathrm{TbB}_{4}$ & $12-15$ & Ar & 4 & $15-25$ \\
\hline $\mathrm{DyB}_{4}$ & 18 & Ar & 2 & $20-25$ \\
\hline $\mathrm{HoB}_{4}$ & $5-18$ & Ar & $3-5$ & $15-20$ \\
\hline $\mathrm{ErB}_{4}$ & $10-15$ & Ar & $2-3$ & $15-25$ \\
\hline $\mathrm{TmB}_{4}$ & $15-18$ & Ar & $5-6$ & $15-25$ \\
\hline $\mathrm{YB}_{4}$ & 20 & Ar & 6 & $20-25$ \\
\hline
\end{tabular}

With the exception of $\mathrm{NdB}_{4}$, all $\mathrm{RB}_{4}$ materials appear to melt congruently. For all the growths, a dark-gray colored deposition was observed on the quartz tube surrounding the feed and seed rods, indicating the evaporation of boron during the growth process.

Crystal samples were obtained for all the growth conditions employed and single crystals large enough for the physical property measurements could be isolated from the as-grown boules. The crystal boules prepared were typically $2-6 \mathrm{~mm}$ in diameter and $30-50 \mathrm{~mm}$ long. Phase purity analysis was carried out by powdering small pieces of the crystals to perform X-ray diffraction measurements. Extensive $\mathrm{X}$-ray Laue analysis of the as-grown boules of $R \mathrm{~B}_{4}$ usually revealed the presence of 2-3 grains, extending along the length of each of the boules. The grain boundaries were not visible by eye; however, these grains can be isolated to give single crystals typically $5 \mathrm{~mm}$ in length and diameter. A selection of Laue photographs taken along the length and the cross section of a $\mathrm{HoB}_{4}$ crystal boule is shown in Figure 2. This is representative of the other $R B_{4}$ crystals grown. $\mathrm{X}$-ray Laue photographs were taken at $3 \mathrm{~mm}$ intervals along the length of two sides of the $\mathrm{HoB}_{4}$ boule. Identical patterns were obtained for the first $10 \mathrm{~mm}$ of the crystal boule, and a second grain is observed for the remaining length of the boule (see Figure 2). The corresponding Laue patterns taken on the side at 180 degrees are mirror images of these patterns. Laue photographs taken of the cross section of the boule show consistent Laue patterns at several positions, one of which is shown in Figure 2. We did not observe a consistent growth direction for any of the rare-earth tetraborides crystal boules prepared.

When the $R \mathrm{~B}_{4}$ (with $R=\mathrm{Nd}$, Ho, Er, and Tm) crystals were required for neutron scattering experiments, isotopically enriched boron, ${ }^{11} \mathrm{~B}$, was used for the preparation of the polycrystalline material in order to reduce the neutron absorption by naturally occurring boron.

The results of the crystal growth of each of the rare-earth tetraborides are discussed in more detail below. 

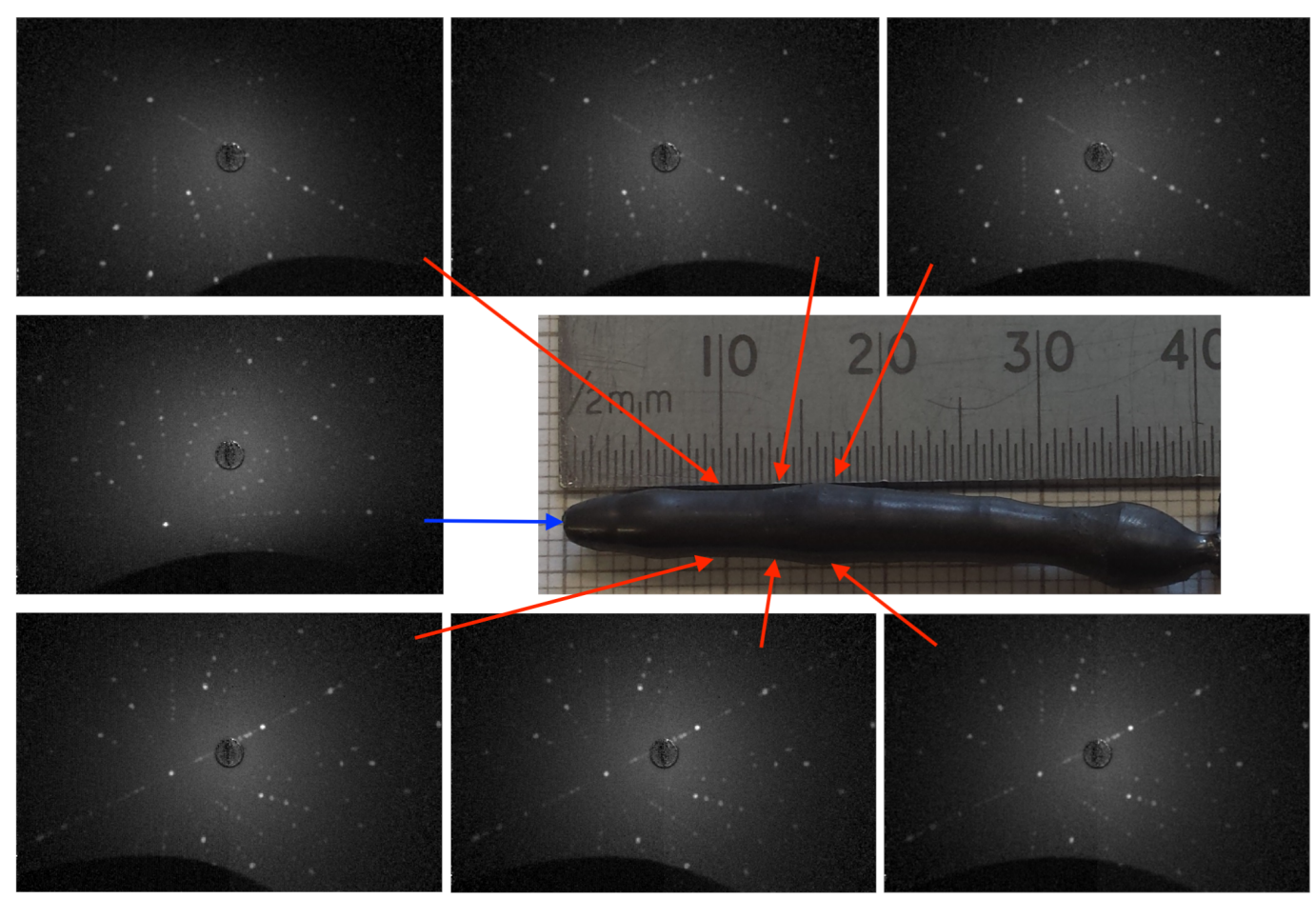

Figure 2. Photograph of a portion of an as-grown boule of $\mathrm{HoB}_{4}$ prepared by the floating-zone technique. Also shown above the image of the crystal are the X-ray Laue patterns of one of the sides, taken along the crystal length at $3 \mathrm{~mm}$ intervals. The corresponding Laue patterns taken on the side at 180 degrees (shown below the photograph of the boule) are mirror images of these patterns. Laue patterns taken of the cross section of the end of the boule, are consistent with one another at several points. One Laue photograph corresponding to scans across the diameter of the crystal is shown.

\subsection{1. $\mathrm{NdB}_{4}$}

The as-grown boule of $\mathrm{NdB}_{4}$ is shown in Figure 3a. The crystal boule is partially coated with a blue residue. The phase diagram of the Nd-B system shows that at $2400{ }^{\circ} \mathrm{C}, \mathrm{NdB}_{4}$ melts peritectically into $\mathrm{NdB}_{6}$ and a $\mathrm{Nd}$-rich liquid $[30,36]$. Previous literature also reports that $\mathrm{NdB}_{4}$ decomposes to form $\mathrm{NdB}_{6}$ above $1800^{\circ} \mathrm{C}$ according to the reaction equation [24,36]:

$$
2 \mathrm{NdB}_{4} \longrightarrow \mathrm{NdB}_{6}+\mathrm{Nd}+2 \mathrm{~B},
$$

due to the volatility of the neodymium metal and B-B distances [36]. We believe that the impurity seen on the surface of the crystal boule is $\mathrm{NdB}_{6}$, due to this disassociation. The impurity was generally confined to the surface and could be removed easily to isolate reasonably sized single crystals of $\mathrm{NdB}_{4}$. The good crystallinity of the isolated single crystals was confirmed by X-ray Laue diffraction (shown in Figure 3b).

Phase purity analysis was carried out and the diffractogram for $\mathrm{NdB}_{4}$ is shown in Figure $3 \mathrm{c}$. Profile matching (goodness of fit $(\mathrm{GOF})=1.70$ ) indicates that the main phase is $\mathrm{NdB}_{4}$ and that there is an impurity phase of $\mathrm{NdB}_{6}$ as expected from the decomposition reaction given in Equation (3). The space group is $P 4 / \mathrm{mbm}$ and the lattice parameters calculated from the profile matching were determined to be $a=7.21993$ (3) $\AA$ and $c=4.10330(2) \AA$. These agree with previously published results $[37,38]$. 


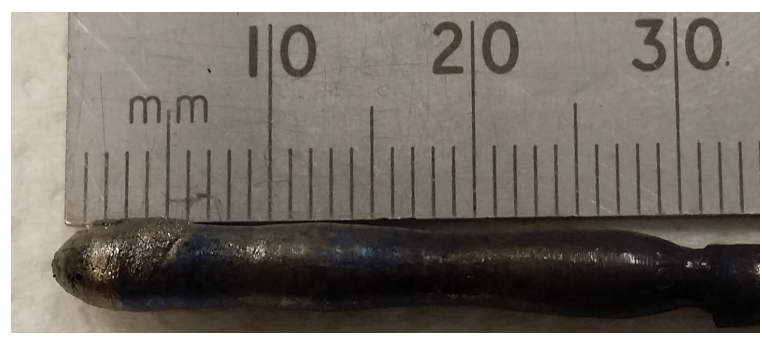

(a)

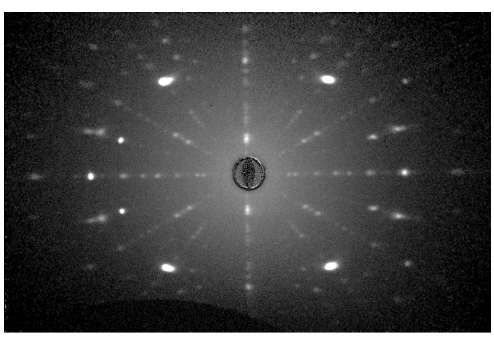

(b)

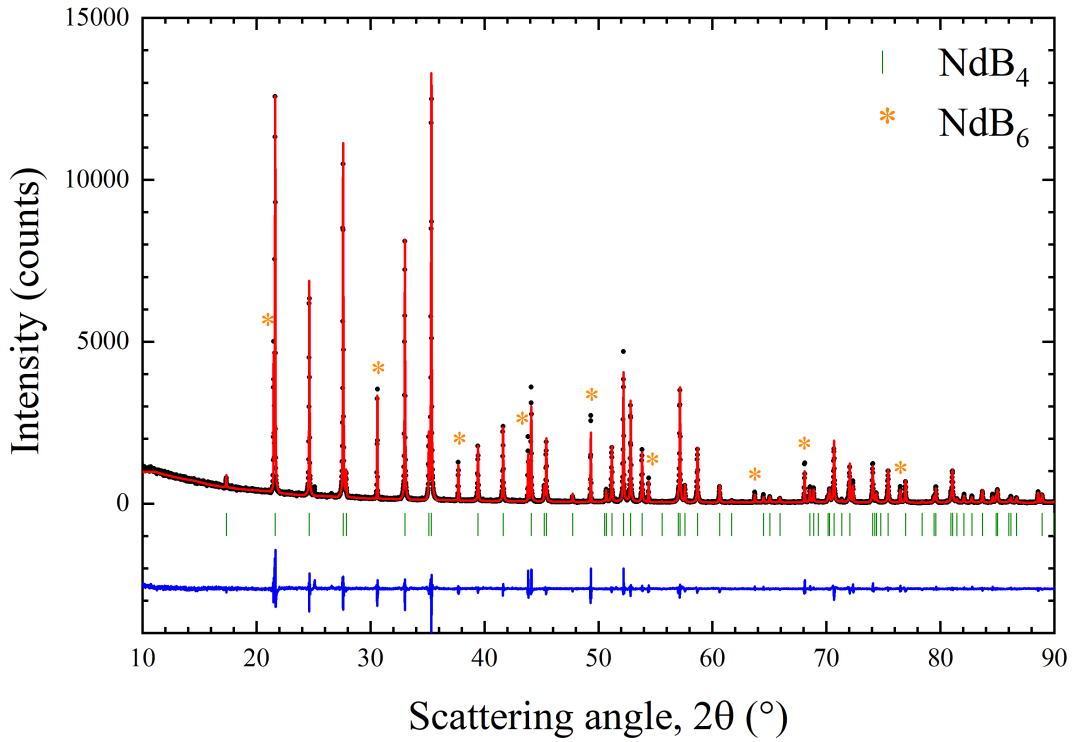

(c)

Figure 3. (a) Boule of $\mathrm{NdB}_{4}$ prepared by the floating-zone method in an argon atmosphere at a growth rate of $15 \mathrm{~mm} / \mathrm{h}$. (b) X-ray Laue back reflection photograph of a crystal of $\mathrm{NdB}_{4}$, showing the [100] orientation of an aligned sample used for physical properties measurements. (c) Room temperature powder X-ray diffraction pattern of a ground $\mathrm{NdB}_{4}$ crystal. The experimental profile (black closed circles) and a full profile matching refinement (red solid line) made using the $\mathrm{P} 4 / \mathrm{mbm}$ tetragonal structure are shown, with the difference given by the blue solid line. The symbols * indicate the reflections belonging to a $\mathrm{NdB}_{6}$ impurity.

Composition analysis by EDAX focused on the main part of the crystal as well as the areas of blue. This showed that the cationic ratio averages of 1:4 and 1:6 for Nd:B for the bulk of the crystal and blue regions, respectively. The average atomic percentages of $\mathrm{Nd}$ and $\mathrm{B}$ were $(18.5 \pm 0.7) \%$ and $(81.5 \pm 0.2) \%$ respectively, which is in good agreement with the expected theoretical values of $20 \%$ for $\mathrm{Nd}$ and $80 \%$ for B. While the average atomic percentages of $\mathrm{Nd}$ and $\mathrm{B}$ in the blue regions is $(15.6 \pm 0.1) \%$ and $(84.4 \pm 0.4) \%$ respectively are also in reasonable agreement with the expected values of $14.3 \%$ and $85.7 \%$ for a ratio of 1:6 for Nd:B.

Temperature dependent magnetization measurements for $\mathrm{NdB}_{4}$ for $H \| c$ and $H \perp c$ are shown in Figure $4 \mathrm{a}$,b respectively. Magnetic susceptibility measurements in a field of $5 \mathrm{kOe}$ show successive phase transitions for $H \| c$. The transitions are seen as a broad maximum at $7 \mathrm{~K}$ followed by a small discontinuous drop at $4.2 \mathrm{~K}$. Measurements for $H \perp c$ show an additional transition at $T=17 \mathrm{~K}$. The evolution of the magnetic susceptibility in larger magnetic fields is also shown. The change of the transition temperatures with an increasing magnetic field is consistent with the previously published phase diagram [39].

The temperature dependent resistivity measurements for $H \| c$ where the current was applied along the [110] direction is shown in Figure 4c. The resistivity is linear from approximately $20 \mathrm{~K}$ up to $300 \mathrm{~K}$ indicating the metallic nature of the $\mathrm{RB}_{4}$ family of compounds. The $\mathrm{NdB}_{4}$ crystal used has a 
high residual resistance ratio (RRR), with $\rho(300 \mathrm{~K}) / \rho(2 \mathrm{~K})>100$, confirming the low density of defects in the crystal.

The resistivity in a small magnetic field of 100 Oe shows three successive features at 17, 7.2 and $4.9 \mathrm{~K}$ consistent with the magnetic susceptibility measurements presented in Figure $4 \mathrm{a}, \mathrm{b}$ as well as the previously published phase diagram [39]. Further discussion of the resistivity measurements and data can be found in Ref. [40].

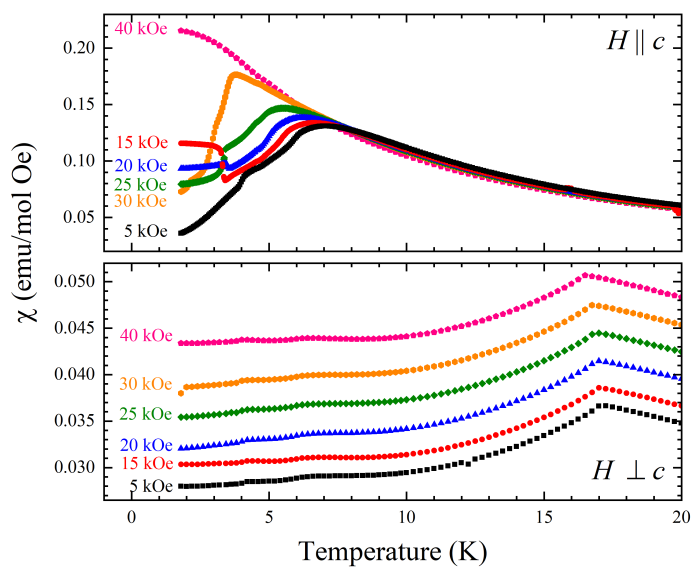

(a)

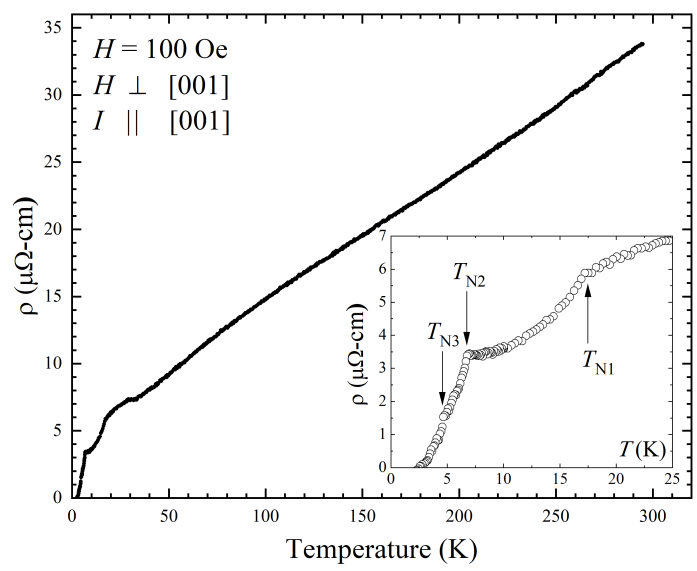

(b)

Figure 4. (a) Temperature dependent magnetic susceptibility measurements for $\mathrm{NdB}_{4}$ in magnetic fields between 5 and $40 \mathrm{kOe}$ for $H \| c$ (top left) and $H \perp c$ (bottom left). For $H \perp c$ each curve is offset by $0.003 \mathrm{emu} / \mathrm{mol}$ Oe. (b) Temperature dependent resistivity measurements for a single crystal of $\mathrm{NB}_{4}$ with $H \perp c$ in a magnetic field of 100 Oe. Inset: low temperature $\rho(T)$ for $\mathrm{NdB}_{4}$.

\subsection{2. $\mathrm{GdB}_{4}$}

The as-grown boule of $\mathrm{GdB}_{4}$ is shown in Figure 5 a. Unlike $\mathrm{NdB}_{4}$ there is no coating of impurity on the exterior of the boule. The quality of the crystal was checked using $\mathrm{X}$-ray Laue diffraction and the Laue photograph along the [100] direction is shown in Figure $5 b$.

Phase analysis by powder X-ray diffraction is shown in Figure $5 \mathrm{c}$. The diffractogram indicates the main phase is $\mathrm{GdB}_{4}$; however, there is a $\mathrm{GdB}_{6}$ impurity. Unlike $\mathrm{NdB}_{4}, \mathrm{GdB}_{4}$ does not thermally decompose, and so this is impurity probably arises because $\mathrm{GdB}_{4}$ and $\mathrm{GdB}_{6}$ have very similar melting points of $2650^{\circ} \mathrm{C}$ and $2510^{\circ} \mathrm{C}$ respectively [31,36]. Additionally, there are two Bragg peaks (indicated with an + in Figure $5 \mathrm{c}$ ) which could not be indexed with the $P 4 / m b m$ space group, and likely arise due to the presence of a small quantity of a $\mathrm{Gd}_{2} \mathrm{~B}_{5}$ impurity. More detailed investigations are necessary to further optimize the conditions for the synthesis of both the polycrystalline starting materials as well as for the crystal growth, to avoid the presence of these small levels of intergrowths of subsidiary phases in $\mathrm{GdB}_{4}$, and these are in progress. The lattice parameters were determined by profile matching $(\mathrm{GOF}=1.36)$ and were determined to be $a=7.1435(2) \AA$ and $c=4.0473(2) \AA$. These agree with previously published results $[37,41]$. 


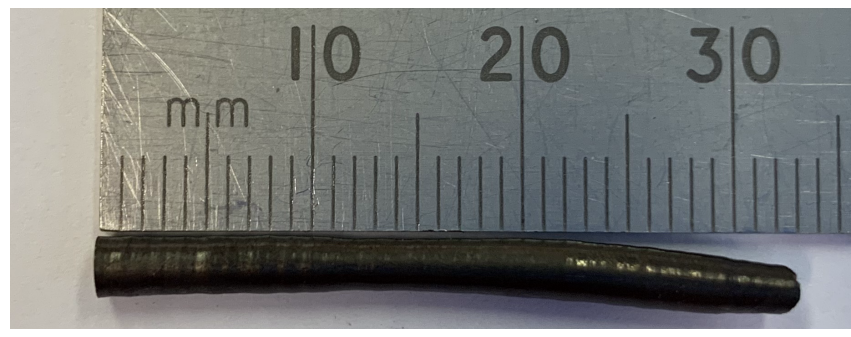

(a)

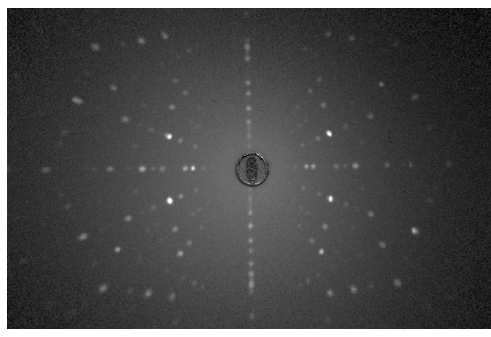

(b)

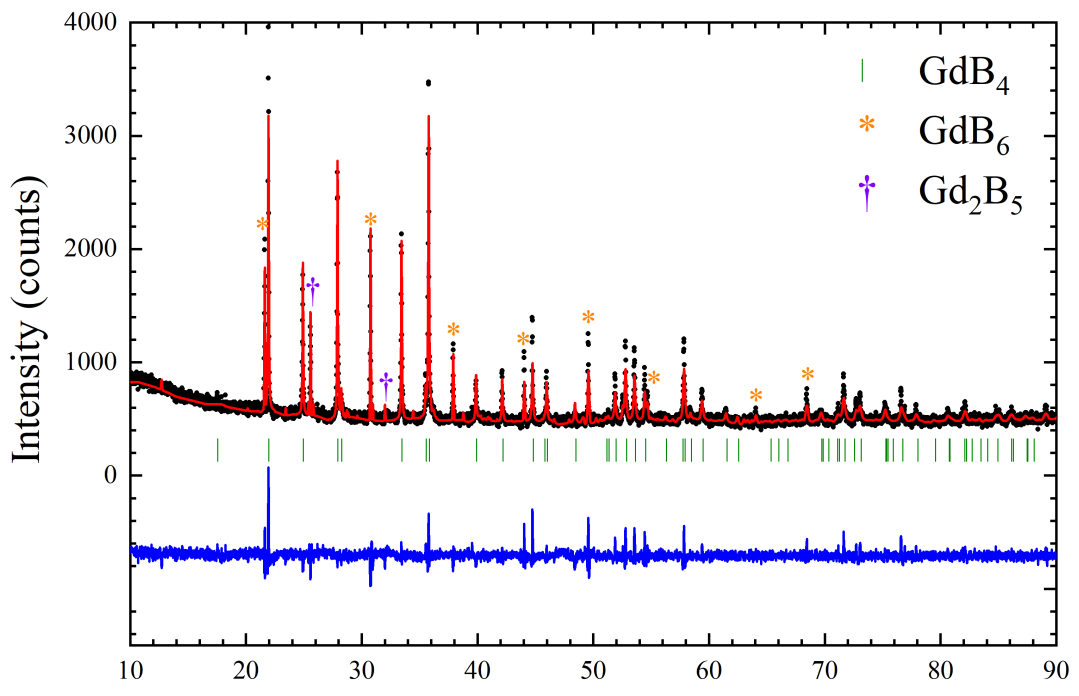

Scattering angle, $2 \theta\left(^{\circ}\right)$

(c)

Figure 5. (a) Boule of $\mathrm{GdB}_{4}$ prepared by the floating-zone method in an argon atmosphere at a growth rate of $18 \mathrm{~mm} / \mathrm{h}$. (b) X-ray Laue back reflection photograph of a crystal of $\mathrm{GdB}_{4}$, showing the [100] orientation of an aligned sample used for physical properties measurements. (c) Room temperature powder X-ray diffraction pattern of a ground $\mathrm{GdB}_{4}$ crystal. The experimental profile (black closed circles) and a full profile matching refinement (red solid line) made using the $\mathrm{P} 4 / \mathrm{mbm}$ tetragonal structure are shown, with the difference given by the blue solid line. The symbols * indicate the reflections belonging to $\mathrm{GdB}_{6}$ impurity and the + indicates a $\mathrm{Gd}_{2} \mathrm{~B}_{5}$ impurity.

\subsection{3. $\mathrm{DyB}_{4}$}

The as-grown boule of $\mathrm{DyB}_{4}$ is shown in Figure 6a. Most of the exterior of the boule has the typical dull gray color indicative of the tetraboride, but there is also a small blue region where the melt dripped on to the crystal. This blue region is indicative of the hexaboride formation, similar to that observed in $\mathrm{NdB}_{4}$. Powder $\mathrm{X}$-ray diffraction phase purity analysis was carried out (shown in Figure 6c) on a piece of a crystal selected from outside this area and indicated that the main phase is $\mathrm{DyB}_{4}$, with no significant impurity phases. The lattice parameters were determined by profile matching (GOF $=1.23)$ and were determined to be $a=7.0989(3) \AA$ and $c=4.0183(2) \AA$. These are in agreement with previously published results [12,37]. A representative Laue along the [001] direction (shown in Figure $6 b$ ) confirms the good crystallinity of the isolated crystals. 


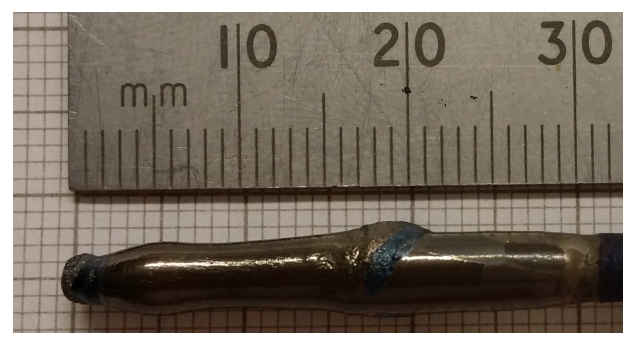

(a)

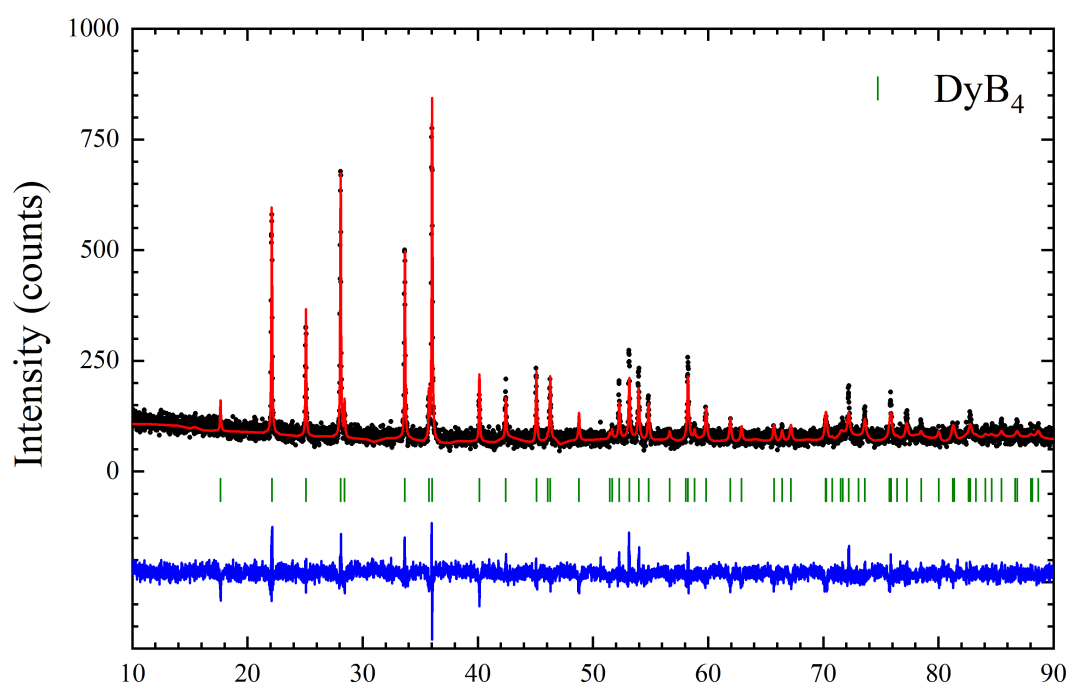

Scattering angle, $2 \theta\left(^{\circ}\right)$

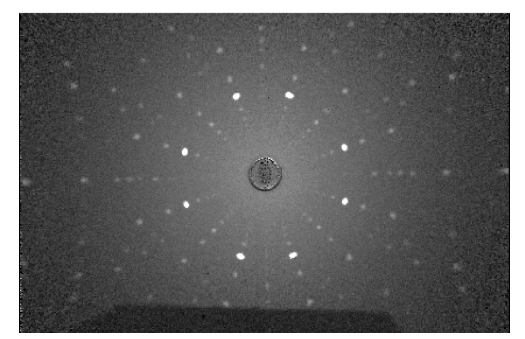

(b)

(c)

Figure 6. (a) Boule of $\mathrm{DyB}_{4}$ prepared by the floating-zone method in an argon atmosphere at a growth rate of $18 \mathrm{~mm} / \mathrm{h}$. (b) X-ray Laue back reflection photograph of a crystal of $\mathrm{DyB}_{4}$, showing the [001] orientation of an aligned sample used for physical properties measurements. (c) Room temperature powder X-ray diffraction pattern of a ground $\mathrm{DyB}_{4}$ crystal. The experimental profile (black closed circles) and a full profile matching refinement (red solid line) made using the $\mathrm{P} 4 / \mathrm{mbm}$ tetragonal structure are shown, with the difference given by the blue solid line.

The temperature dependence of the magnetic susceptibility of $\mathrm{DyB}_{4}$ for $H \| c$ and $H \perp c$ is shown in Figure 7. For $H \| c, \mathrm{DyB}_{4}$ shows successive magnetic phase transitions. The first is observed as a broad maximum at approximately $21 \mathrm{~K}$ and this is then followed by a small change in gradient at $12 \mathrm{~K}$. These magnetic transitions are also observed for $H \perp c$; however, the higher temperature feature is less pronounced, while the lower temperature cusp is enhanced. In Figure 7, phase I is paramagnetic and phases II and III have different collinear antiferromagnetic structures. Information on the nature of these magnetic phases has been reported elsewhere [42,43]. Field-dependent magnetization measurements (not shown) are consistent with the magnetic phase diagram previously published [43]. 


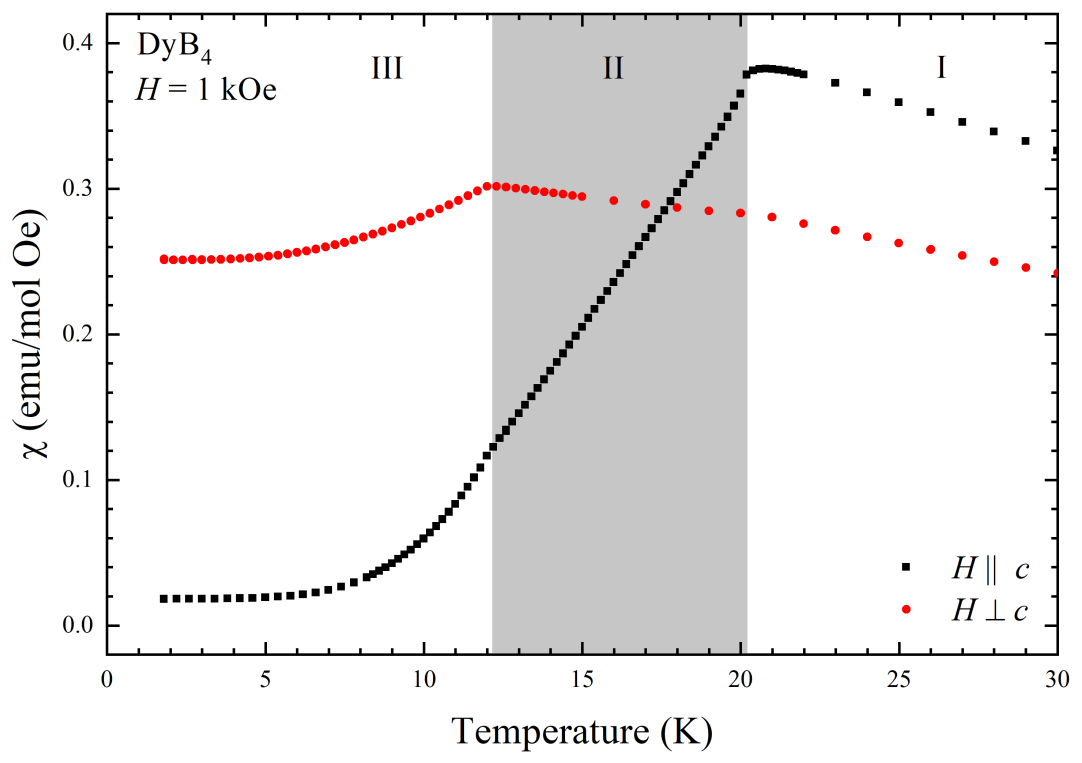

Figure 7. Temperature dependent magnetic susceptibility of $\mathrm{DyB}_{4}$ in a field of $1 \mathrm{kOe}$ for $H \| c$ and $H \perp c$.

\subsection{4. $\mathrm{HoB}_{4}$}

A boule of $\mathrm{HoB}_{4}$ is shown in Figure 8a. The high crystallinity of the crystal was confirmed with X-ray Laue diffraction and a Laue photograph along the [001] direction is shown in Figure 8b.

Phase purity analysis shows that the main phase is $\mathrm{HoB}_{4}$, with no significant impurity phases present. Profile matching $(\mathrm{GOF}=2.36)$ was carried out and the lattice parameters were determined to be $a=7.08674(3) \AA$ and $c=4.00825(2) \AA$. These agree with previously published results $[23,37,44]$. A few peaks that do not belong to the $P 4 / \mathrm{mbm}$ space group can be observed in the powder X-ray profile of $\mathrm{HoB}_{4}$, shown in Figure 8c; however, due to their extremely reduced intensities, the impurity phase could not be identified.

Temperature dependent resistivity for $H \| c$ and $H \perp c$ for $\mathrm{HoB}_{4}$ is shown in Figure 9a,b, respectively. In both cases, the current was applied along the [100] direction. Again, the resistivity is linear from approximately $10 \mathrm{~K}$ up to $300 \mathrm{~K}$ indicating the metallic nature of $\mathrm{HoB}_{4}$. The $\mathrm{HoB}_{4}$ crystal has a residual resistance ratio (RRR) $>20$. The resistivity measurements for both $H \| c$ and $H \perp c$ $(H \| a)$ show the presence of two features occurring at approximately 7.2 and $5.2 \mathrm{~K}$. For $H \| c$ both transitions are suppressed in increasing magnetic fields. For $H \perp c$ the transition at approximately $7.2 \mathrm{~K}$ remains constant, whereas the feature at $5.2 \mathrm{~K}$ is suppressed with increasing magnetic field. This behavior is consistent with the previously published magnetic phases diagrams for $\mathrm{HoB}_{4}$ [45].

\subsection{5. $\mathrm{ErB}_{4}$}

The as-grown boule of $\mathrm{ErB}_{4}$ is shown in Figure 10a and the quality of the crystal was confirmed through use of X-ray Laue diffraction (shown in Figure 10b). Phase purity analysis using powder $X$-ray diffraction is shown in Figure 10c. The main phase corresponds to $\mathrm{ErB}_{4}$; however, there is a small quantity of an $\mathrm{ErB}_{12}$ impurity phase. $\mathrm{ErB}_{4}$ does not thermally decompose, but $\mathrm{ErB}_{4}, \mathrm{ErB}_{2}$ and $\mathrm{ErB}_{12}$ have similar melting points $\left(2500,2185\right.$ and $2080^{\circ} \mathrm{C}$ respectively $\left.[33,36]\right)$. As a result, $\operatorname{ErB}_{12}$ is probably forming during the synthesis of the precursors and the crystal growth. Additionally, there are two Bragg peaks (indicated with a + in Figure 10c) which could not be indexed with the $P 4 / \mathrm{mbm}$ space group, likely arising from an $\mathrm{ErB}_{2}$ impurity. Subsequent growths eliminated this impurity. The lattice parameters were determined to be $a=7.0705(1) \AA$ and $c=3.99710(8) \AA$ by profile matching (GOF $=1.90$ ) and are in agreement with previous studies $[37,46]$. 


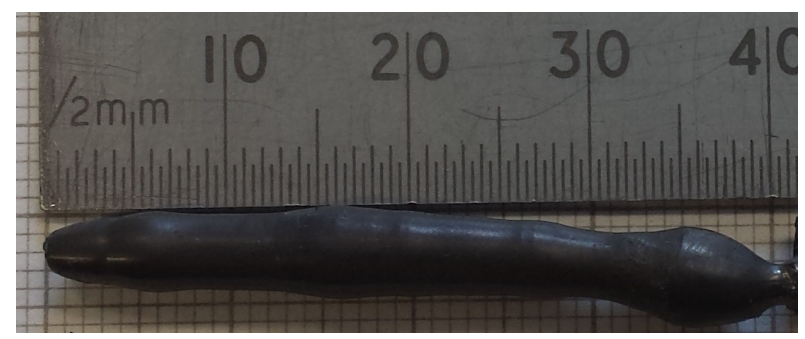

(a)

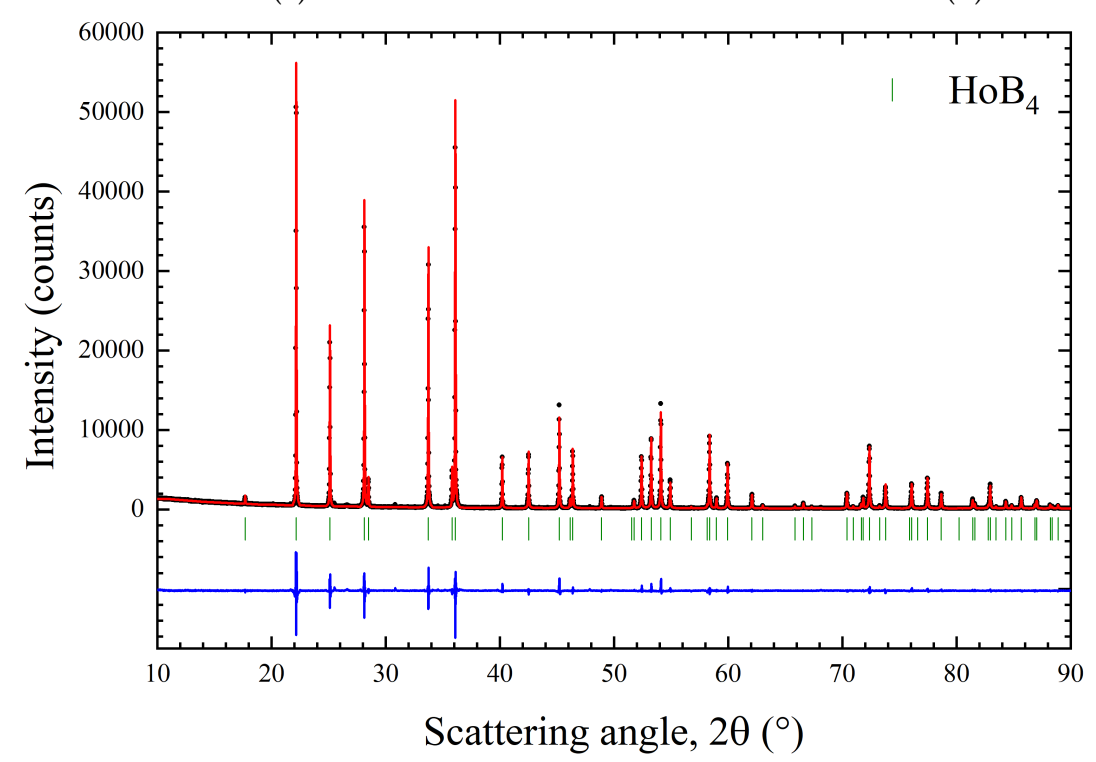

(c)

(b)

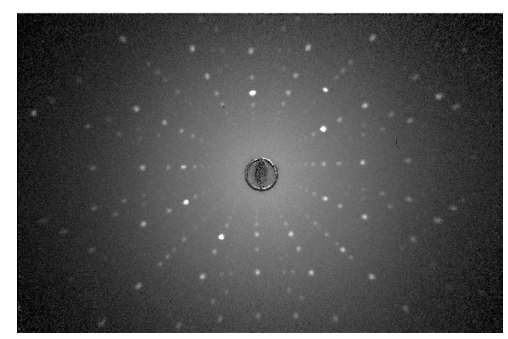

Figure 8. (a) Boule of $\mathrm{HoB}_{4}$ prepared by the floating-zone method in an argon atmosphere at arowth rate of $15 \mathrm{~mm} / \mathrm{h}$. (b) X-ray Laue back reflection photograph of a crystal of $\mathrm{HoB}_{4}$, showing the [001] orientation of an aligned sample used for physical properties measurements. (c) Room temperature powder X-ray diffraction pattern of a piece of ground $\mathrm{HoB}_{4}$ crystal. The experimental profile (black closed circles) and a full profile matching refinement (red solid line) made using the $P 4 / \mathrm{mbm}$ tetragonal structure are shown, with the difference given by the blue solid line.

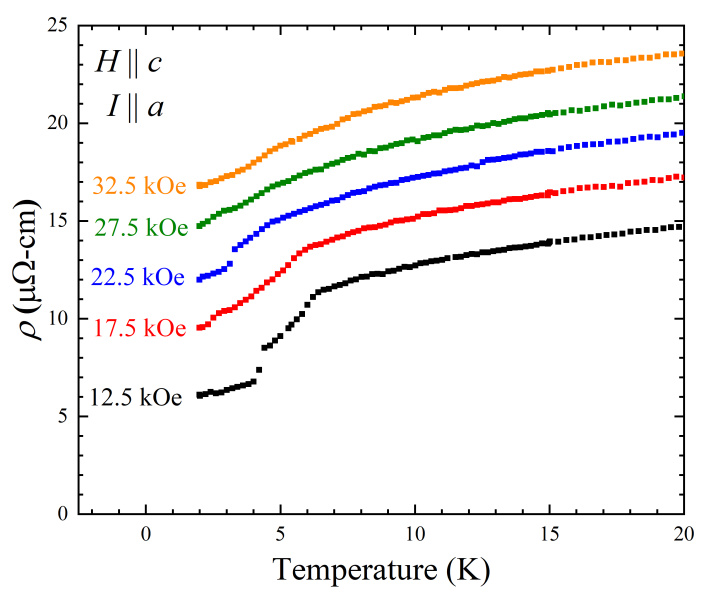

(a)

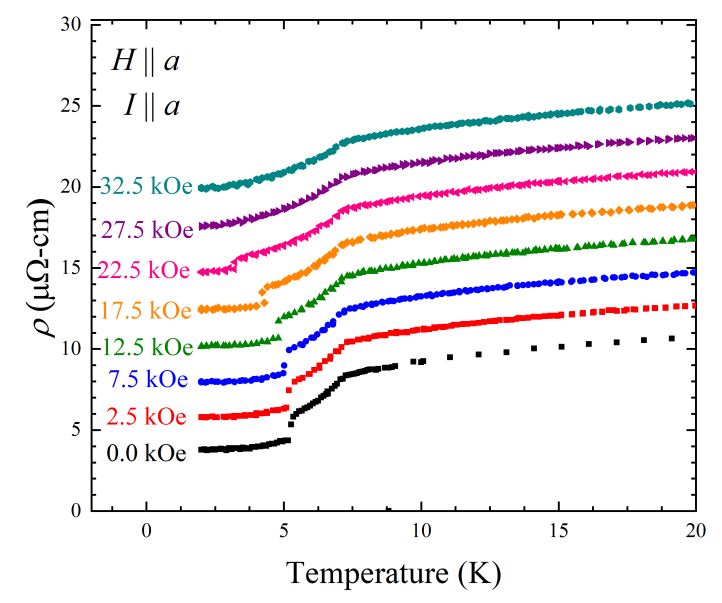

(b)

Figure 9. Temperature dependent $\mathrm{AC}$ resistivity measurements for $\mathrm{HoB}_{4}$ for (a) $H \| c$ and (b) $H \perp c$ in magnetic fields up to $32.5 \mathrm{kOe}$. Each curve is offset by $2 \mu \Omega$-cm. 


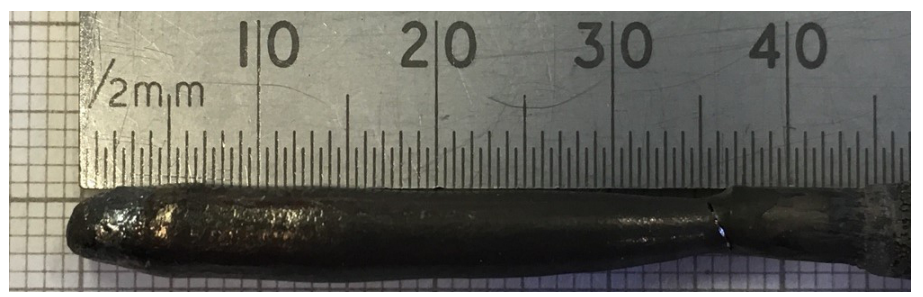

(a)

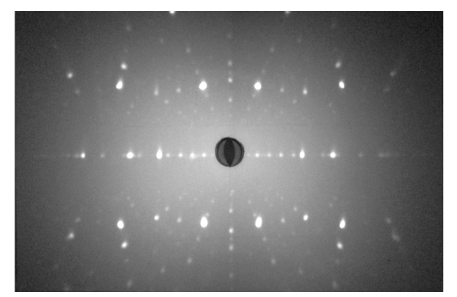

(b)

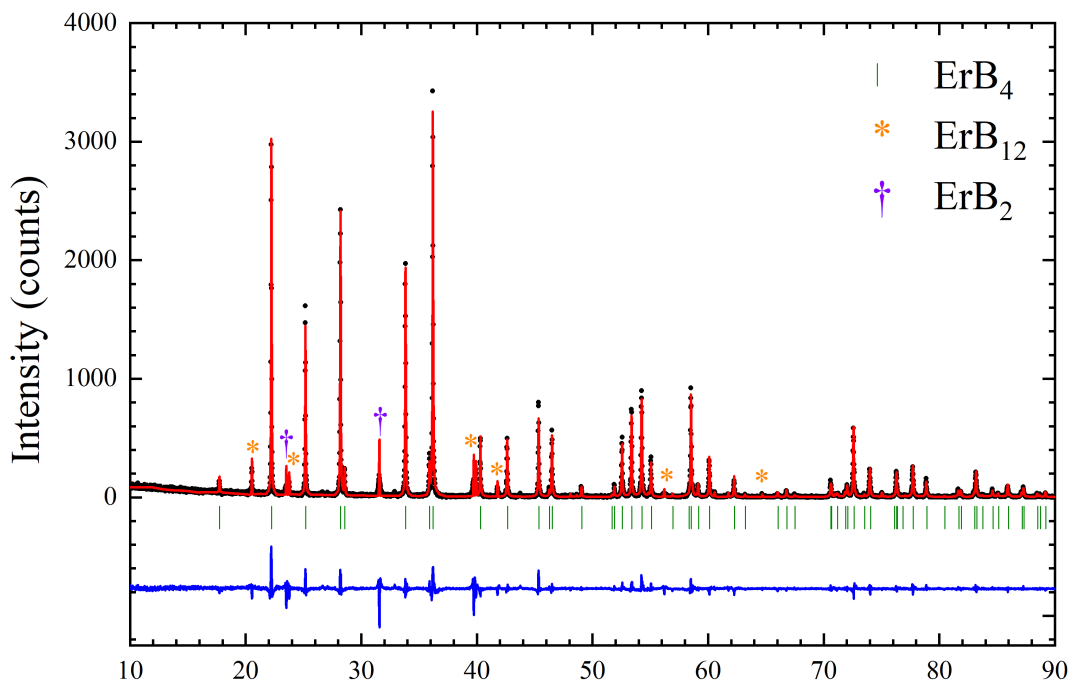

Scattering angle, $2 \theta\left(^{\circ}\right)$

(c)

Figure 10. (a) Boule of $\mathrm{ErB}_{4}$ prepared by the floating-zone method in an argon atmosphere at a growth rate of $10 \mathrm{~mm} / \mathrm{h}$. (b) X-ray Laue back reflection photograph of a crystal of $\mathrm{ErB}_{4}$, showing the [110] orientation of an aligned sample used for physical properties measurements. (c) Room temperature powder X-ray diffraction pattern of a ground $\mathrm{ErB}_{4}$ crystal. The experimental profile (black closed circles) and a full profile matching refinement (red solid line) made using the $P 4 / \mathrm{mbm}$ tetragonal structure are shown, with the difference given by the blue solid line. The symbols * indicate the reflections belonging to an $\mathrm{ErB}_{12}$ impurity and the t indicates an $\mathrm{ErB}_{2}$ impurity.

\subsection{6. $\mathrm{TmB}_{4}$}

A $\mathrm{TmB}_{4}$ crystal grown is shown in Figure 11a and a Laue photograph obtained along the [100] direction is shown in Figure 11b, confirming the excellent crystallinity of the crystals produced.

Phase purity analysis shows the main phase is $\mathrm{TmB}_{4}$. Only a single Bragg peak could not be indexed in the $P 4 / \mathrm{mbm}$ space group, and reveals the presence of a small amount of a $\operatorname{Tm}_{2} \mathrm{O}_{3}$ impurity. For the subsequent growths, no sign of impurities was observed. The lattice parameters were determined to be $a=7.05563(8) \AA$ and $c=3.98605(5) \AA$ by profile matching (GOF = 1.92) and are in agreement with previous measurements [23,47]. Composition analysis by EDAX of the crystal of $\mathrm{TmB}_{4}$ shows that for the entire length of the crystal boule, the average atomic percentages of $\mathrm{Tm}$ and $\mathrm{B}$ were $(23.3 \pm 0.4) \%$ and $(76.7 \pm 0.4) \%$ respectively, in good agreement with the expected $1: 4$ ratio for Tm:B. 


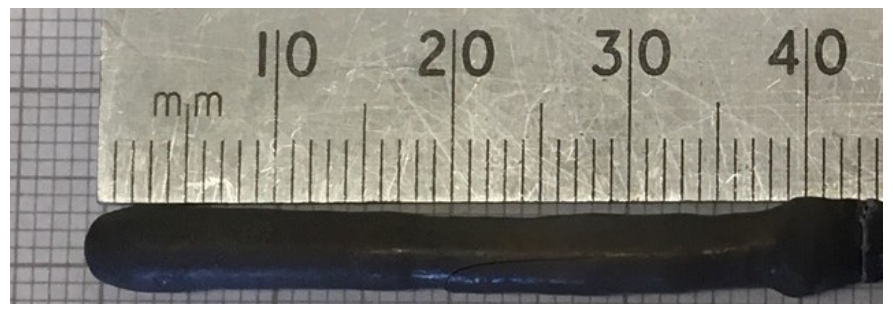

(a)

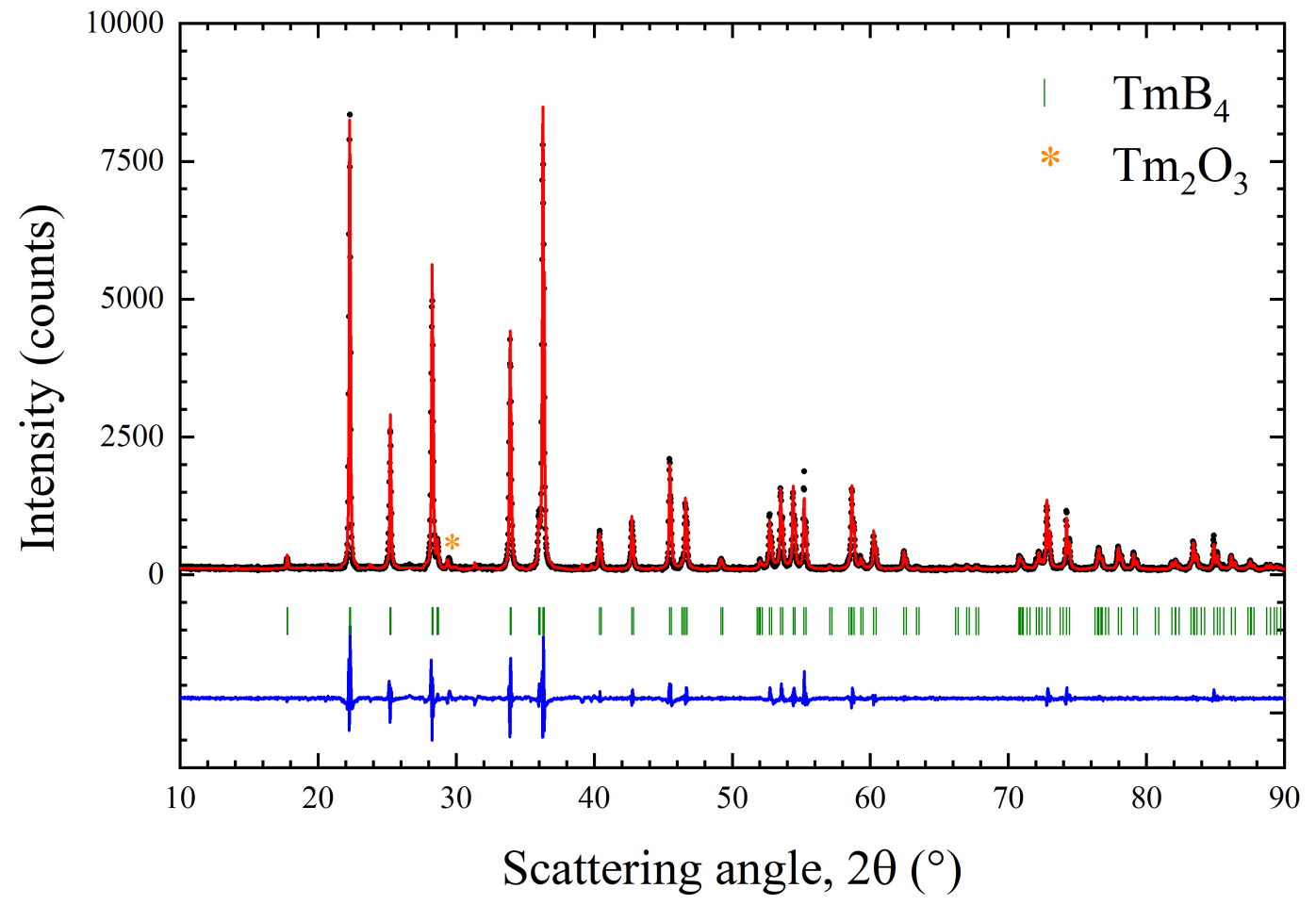

(c)

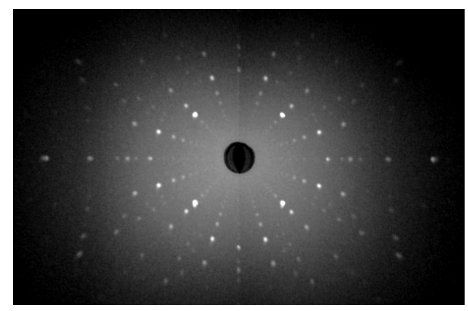

(b)

Figure 11. (a) Boule of $\mathrm{TmB}_{4}$ prepared by the floating-zone method in an argon atmosphere at a growth rate of $18 \mathrm{~mm} / \mathrm{h}$. (b) X-ray Laue back reflection photograph of a crystal of $\mathrm{TmB}_{4}$, showing the [001] orientation of an aligned sample used for physical properties measurements. (c) Room temperature powder X-ray diffraction pattern of a ground $\mathrm{TmB}_{4}$ crystal. The experimental profile (black closed circles) and a full profile matching refinement (red solid line) made using the $\mathrm{P} 4 / \mathrm{mbm}$ tetragonal structure are shown, with the difference given by the blue solid line. The symbols * indicate the reflections belonging to a $\mathrm{Tm}_{2} \mathrm{O}_{3}$ impurity.

\subsection{7. $\mathrm{TbB}_{4}$ and $\mathrm{YB}_{4}$}

Crystals of $\mathrm{TbB}_{4}$ and $\mathrm{YB}_{4}$ were also grown. The quality of the crystals is confirmed by the $\mathrm{X}$-ray Laue photographs shown alongside the photographs of the crystals in Figure 12a,b. 
(a) $\mathrm{TbB}_{4}$

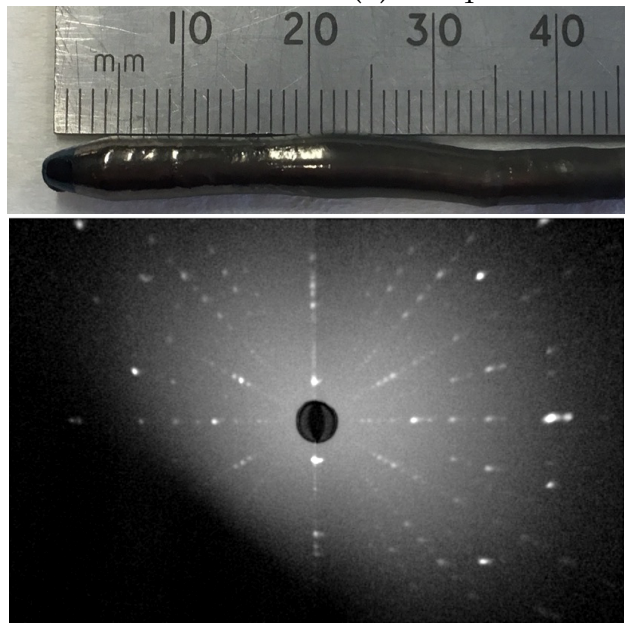

(b) $\mathrm{YB}_{4}$

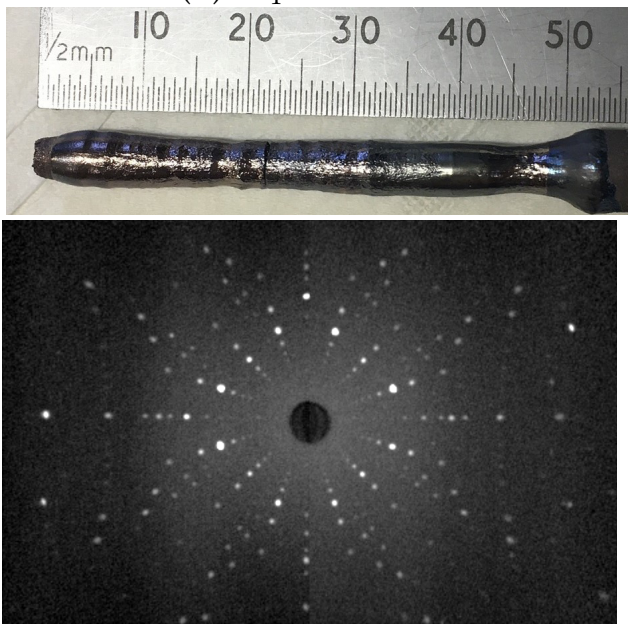

Figure 12. (a) Boule of $\mathrm{TbB}_{4}$ prepared by the floating-zone method in an argon atmosphere at a growth rate of $15 \mathrm{~mm} / \mathrm{h}$, and $\mathrm{X}$-ray Laue back reflection photograph, showing the [110] orientation. (b) Boule of $\mathrm{YB}_{4}$ prepared by the floating-zone method in an argon atmosphere at a growth rate of $20 \mathrm{~mm} / \mathrm{h}$, and X-ray Laue back reflection photograph, showing the [001] orientation.

\section{Summary}

We have been successful in growing large single crystals of rare-earth tetraborides, $R B_{4}$ (where $R=\mathrm{Nd}, \mathrm{Gd} \rightarrow \mathrm{Tm}$, and $\mathrm{Y}$ ) by the floating-zone technique. The growth conditions employed are given in Table 1 . The quality and composition of the as-grown boules were investigated using $\mathrm{X}$-ray diffraction techniques. The lattice parameters determined from this analysis are collected in Table 2. Despite the intergrowth and stabilization of other boride phases due to similar melting temperatures, large crystals of $R B_{4}$ could still be isolated from the as-grown boules. Detailed studies are in progress to understand the stabilization of the $R \mathrm{~B}_{4}$ phase and to further optimize the crystal growth conditions. The size and the good quality of the crystals grown make them suitable for most physical properties characterization experiments, such as magnetization and neutron-scattering studies. Investigations of the low temperature magnetic behavior were carried out on some of these $R \mathrm{~B}_{4}$ crystals and the results were found to be consistent with previous results.

Table 2. Lattice parameters calculated from profile matching the powder X-ray diffraction patterns of the $R \mathrm{~B}_{4}$ samples to the $\mathrm{P} 4 / \mathrm{mbm}$ tetragonal structure. The previously reported structural parameters quoted are taken from Refs. [37,47]. Additional references quoting structural parameters for each member of the series are included for completeness.

\begin{tabular}{ccccccc}
\hline & & & \multicolumn{3}{c}{ Previous Literature } \\
\cline { 2 - 7 } $\boldsymbol{R}$ & \multicolumn{2}{c}{ Lattice Parameters } & GOF & \multicolumn{2}{c}{ Lattice Parameters } & Refs. \\
\cline { 2 - 7 } & $\boldsymbol{a}(\AA \mathbf{(})$ & $\boldsymbol{c}(\AA)$ & & $\boldsymbol{a}(\AA)$ & $\boldsymbol{c}(\AA)$ \\
\hline Nd & $7.21993(3)$ & $4.10330(2)$ & 1.70 & $7.219(1)$ & $4.1020(5)$ & {$[37,38]$} \\
Gd & $7.1435(2)$ & $4.0473(2)$ & 1.36 & $7.144(1)$ & $4.0479(5)$ & {$[37,41]$} \\
Dy & $7.0989(3)$ & $4.0183(2)$ & 1.23 & $7.101(1)$ & $4.0174(5)$ & {$[12,37]$} \\
Ho & $7.08674(3)$ & $4.00825(2)$ & 2.36 & $7.086(1)$ & $4.0079(5)$ & {$[23,37,44]$} \\
Er & $7.0705(1)$ & $3.99710(8)$ & 1.90 & $7.071(1)$ & $3.9972(5)$ & {$[37,46]$} \\
Tm & $7.05563(8)$ & $3.98605(5)$ & 1.92 & $7.0550(3)$ & $3.9870(3)$ & {$[23,47]$} \\
\hline
\end{tabular}

Author Contributions: D.B. and M.C.H. prepared polycrystalline feed rods by arc melting and borothermal reduction, respectively. G.B. and M.C.H. carried out the crystal growth. D.B. and M.C.H. carried out analysis with X-ray techniques and magnetic characterization. M.R.L. and O.A.P. gave supervision and advice on characterization techniques. D.B. and M.C.H. drafted the paper and all authors reviewed manuscript. 
Funding: This work was funded by EPSRC, UK through Grant EP/M028771/1.

Acknowledgments: The authors would like to acknowledge the contributions of R. Hughes, K. Vaswani, E. Howe, H. Hutchins, G. A. Roles, C. E. Day, B. Higson, P. A. A. Julien to the preparation of rare-earth tetraborides through their involvement with undergraduate projects. The authors would also like to thank T. E. Orton and A. Julian for technical support and S. J. York for the compositional analysis.

Conflicts of Interest: The authors declare no conflict of interest.

\section{References}

1. Ramirez, A.P. Strongly Geometrically Frustrated Magnets. Annu. Rev. Mater. Sci. 1994, 24, 453-480. [CrossRef]

2. Gardner, J.S.; Gingras, M.J.P.; Greedan, J.E. Magnetic pyrochlore oxides. Rev. Mod. Phys. 2010, 82, 53-107. [CrossRef]

3. Schiffer, P.; Ramirez, A.P.; Huse, D.A.; Valentino, A.J. Investigation of the field induced antiferromagnetic phase transition in the frustrated magnet: Gadolinium gallium garnet. Phys. Rev. Lett. 1994, 73, 2500-2503. [CrossRef] [PubMed]

4. Chalker, J.T.; Eastmond, J.F.G. Ground-state disorder in the spin-1/2 kagomé Heisenberg antiferromagnet. Phys. Rev. B 1992, 46, 14201-14204. [CrossRef]

5. Shastry, S.; Sutherland, B. Exact ground state of a quantum mechanical antiferromagnet. Physica B+C 1981, 108, 1069-1070. [CrossRef]

6. Mat'aš, S.; Siemensmeyer, K.; Wheeler, E.; Wulf, E.; Beyer, R.; Hermannsdörfer, T.; Ignatchik, O.; Uhlarz, M.; Flachbart, K.; Gabáni, S.; et al. Magnetism of rare earth tetraborides. J. Phys. Conf. Ser. 2010, 200, 032041. [CrossRef]

7. Takigawa, M.; Waki, T.; Horvatić, M.; Berthier, C. Novel ordered phases in the orthogonal dimer spin system $\mathrm{SrCu}_{2}\left(\mathrm{BO}_{3}\right)_{2}$. J. Phys. Soc. Jpn. 2010, 79, 011005. [CrossRef]

8. Miyahara, S.; Ueda, K. Theory of the orthogonal dimer Heisenberg spin model for $\mathrm{SrCu}_{2}\left(\mathrm{BO}_{3}\right)_{2}$. J. Phys. Condens. Matter 2003, 15, R327. [CrossRef]

9. Okuyama, D.; Matsumura, T.; Nakao, H.; Murakami, Y. Quadrupolar frustration in Shastry-Sutherland lattice of $\mathrm{DyB}_{4}$ studied by resonant X-ray scattering. J. Phys. Soc. Jpn. 2005, 74, 2434-2437. [CrossRef]

10. Werheit, H.; Filipov, V.; Shitsevalova, N.; Armbrüster, M.; Schwarz, U.; Ievdokimova, A.; Muratov, V.; Gurin, V.N.; Korsukova, M.M. Raman scattering in rare earths tetraborides. Solid State Sci. 2014, 31, $24-32$. [CrossRef]

11. Etourneau, J.; Hagenmuller, P. Structure and physical features of the rare-earth borides. Philos. Mag. B 1985, 52, 589-610. [CrossRef]

12. Schäfer, W.; Will, G.; Buschow, K.H.J. The magnetic structure of the rare earth tetraborides $\operatorname{ErB}_{4}$ and $\mathrm{DyB}_{4}$. J. Chem. Phys. 1976, 64, 1994-1997. [CrossRef]

13. Blanco, J.A.; Brown, P.J.; Stunault, A.; Katsumata, K.; Iga, F.; Michimura, S. Magnetic structure of GdB from $^{2}$ spherical neutron polarimetry. Phys. Rev. B 2006, 73, 212411. [CrossRef]

14. Yamauchi, H.; Metoki, N.; Watanuki, R.; Suzuki, K.; Fukazawa, H.; Chi, S.; Fernandez-Baca, J.A. Magnetic structure and quadrupolar order parameter driven by geometrical frustration effect in $\mathrm{NdB}_{4}$. J. Phys. Soc. Jpn. 2017, 86, 044705. [CrossRef]

15. Metoki, N.; Yamauchi, H.; Matsuda, M.; Fernandez-Baca, J.A.; Watanuki, R.; Hagihala, M. Polarized neutron scattering study of the multiple order parameter system $\mathrm{NdB}_{4}$. Phys. Rev. B 2018, 97, 174416. [CrossRef]

16. Okuyama, D.; Matsumura, T.; Iwasa, K.; Murakami, Y. Magnetic phase transition in studied by neutron diffraction. J. Magn. Magn. Mater. 2007, 310, e152-e154. [CrossRef]

17. Michimura, S.; Shigekawa, A.; Iga, F.; Takabatake, T.; Ohoyama, K. Complex Magnetic Structures of a Shastry-Sutherland Lattice $\mathrm{TmB}_{4}$ Studied by Powder Neutron Diffraction Analysis. J. Phys. Soc. Jpn. 2009, 78, 024707. [CrossRef]

18. Brunt, D.; Balakrishnan, G.; Wildes, A.R.; Ouladdiaf, B.; Qureshi, N.; Petrenko, O.A. Field-induced magnetic states in holmium tetraboride. Phys. Rev. B 2017, 95, 024410. [CrossRef]

19. Siemensmeyer, K.; Wulf, E.; Mikeska, H.J.; Flachbart, K.; Gabáni, S.; Mat'aš, S.; Priputen, P.; Efdokimova, A.; Shitsevalova, N. Fractional magnetization plateaus and magnetic order in the Shastry-Sutherland magnet $\mathrm{TmB}_{4}$. Phys. Rev. Lett. 2008, 101, 177201. [CrossRef] 
20. Otani, S.; Korsukova, M.; Mitsuhashi, T.; Kieda, N. Floating zone growth and high-temperature hardness of $\mathrm{YB}_{4}$ and $\mathrm{YB}_{6}$ single crystals. J. Cryst. Growth 2000, 217, 378-382. [CrossRef]

21. Balakrishnan, G.; Lees, M.R.; Paul, D.M. Growth of large single crystals of rare earth hexaborides. J. Cryst. Growth 2003, 256, 206-209. [CrossRef]

22. Ciomaga Hatnean, M.; Lees, M.R.; Paul, D.M.; Balakrishnan, G. Large, high quality single-crystals of the new Topological Kondo Insulator, $\mathrm{SmB}_{6}$. Sci. Rep. 2013, 3, 3071. [CrossRef] [PubMed]

23. Fisk, Z.; Cooper, A.; Schmidt, P.H.; Castellano, R.N. Preparation and lattice parameters of the rare earth tetraborides. Mater. Res. Bull. 1972, 7, 285-288. [CrossRef]

24. Berrada, A.; Mercurio, J.P.; Chevalier, B.; Etourneau, J.; Hagenmuller, P.; Lalanne, M.; Gianduzzo, J.C.; Georges, R. Synthese, cristallogenese, proprietes magnetiques et effets magnetostrictifs spontanes de quelques tetraborures de terres rares. Mater. Res. Bull. 1976, 11, 1519-1526. [CrossRef]

25. Matsumura, T.; Okuyama, D.; Mouri, T.; Murakami, Y. Successive magnetic phase transitions of component orderings in $\mathrm{DyB}_{4}$. J. Phys. Soc. Jpn. 2011, 80, 074701. [CrossRef]

26. Michimura, S.; Shigekawa, A.; Iga, F.; Sera, M.; Takabatake, T.; Kikkawa, A.; Tanaka, Y.; Katsumata, K. Field-induced lattice distortion in single crystal $\mathrm{ErB}_{4}$ observed by X-ray diffraction. J. Magn. Magn. Mater. 2007, 310, e446-e447. [CrossRef]

27. Iga, F.; Shigekawa, A.; Hasegawa, Y.; Michimura, S.; Takabatake, T.; Yoshii, S.; Yamamoto, T.; Hagiwara, M.; Kindo, K. Highly anisotropic magnetic phase diagram of a 2-dimensional orthogonal dimer system $\mathrm{TmB}_{4}$. J. Magn. Magn. Mater. 2007, 310, e443-e445. [CrossRef]

28. Yoshii, S.; Yamamoto, T.; Hagiwara, M.; Michimura, S.; Shigekawa, A.; Iga, F.; Takabatake, T.; Kindo, K. Multistep magnetization plateaus in the Shastry-Sutherland system TbB 4 . Phys. Rev. Lett. 2008, 101, 087202. [CrossRef]

29. Rodríguez-Carvajal, J. Recent advances in magnetic structure determination by neutron powder diffraction. Physica B 1993, 192, 55-69. [CrossRef]

30. Liao, P.K.; Spear, K.E.; Schlesinger, M.E. The B-Nd (boron-neodymium) system. J. Phase Equilibria 1996, 17, 335-339. [CrossRef]

31. Liao, P.K.; Spear, K.E.; Schlesinger, M.E. The B-Gd (boron-gadolinium) system. J. Phase Equilibria 1996, 17, 330-334. [CrossRef]

32. Liao, P.K.; Spear, K.E. The B-Tb (Boron-Terbium) system. Bull. Alloy Phase Diagr. 1990, 11, 325-328. [CrossRef]

33. Liao, P.K.; Spear, K.E.; Schlesinger, M.E. The B-Er (boron-erbium) system. J. Phase Equilibria 1996, 17, $326-329$. [CrossRef]

34. Liao, P.K.; Spear, K.E. The B-Y (boron-yttrium) system. J. Phase Equilibria 1995, 16, 521-524. [CrossRef]

35. Liao, P.K.; Spear, K.E. The lesser-known B-Ln (Boron-Lanthanide) systems: B-Dy (Boron-Dysprosium), B-Ho (Boron-Holmium), B-Lu (Boron-Lutetium), B-Pr (Boron-Praseodymium), B-Tm (Boron-Thulium), and B-Yb (Boron-Ytterbium). J. Phase Equilibria 1998, 19, 49-55.

36. Matkovich, V. (Ed.) Boron and Refractory Borides; Springer: Heidelberg, Germany, 1977.

37. Eick, H.A.; Gilles, P.W. Precise lattice parameters of selected rare earth tetra- and hexa-borides. J. Am. Chem. Soc. 1959, 81, 5030-5032. [CrossRef]

38. Salamakha, P.; Gonçalves, A.; Sologub, O.; Almeida, M. Single crystal investigation of the binary $\mathrm{NdB}_{4}$ compound. J. Alloys Compd. 2001, 316, L4-L6. [CrossRef]

39. Watanuki, R.; Kobayashi, T.; Noguchi, R.; Suzuki, K. Possible multipolar transition in NdB 4 . J. Phys. Conf. Ser. 2009, 150, 042229. [CrossRef]

40. Brunt, D.; Balakrishnan, G.; Mayoh, D.A.; Lees, M.R.; Gorbunov, D.; Qureshi, N.; Petrenko, O.A. Magnetisation process in the rare earth tetraborides, $\mathrm{NdB}_{4}$ and $\mathrm{HoB}_{4}$. Sci. Rep. 2018, 8, 232. [CrossRef]

41. Garland, M.T.; Wiff, J.P.; Bauer, J.; Guérin, R.; Saillard, J.Y. The X-ray and electronic structures of GdB . $_{4}$ Solid State Sci. 2003, 5, 705-710. [CrossRef]

42. Watanuki, R.; Sato, G.; Suzuki, K.; Ishihara, M.; Yanagisawa, T.; Nemoto, Y.; Goto, T. Geometrical quadrupolar frustration in $\mathrm{DyB}_{4}$. J. Phys. Soc. Jpn. 2005, 74, 2169-2172. [CrossRef]

43. Watanuki, R.; Mitamura, H.; Sakakibara, T.; Sato, G.; Suzuki, K. Physical properties and phase diagram of geometrically quadrupolar frustrated system $\mathrm{DyB}_{4}$. Physica B 2006, 378, 594-595. [CrossRef]

44. Okuyama, D.; Matsumura, T.; Mouri, T.; Ishikawa, N.; Ohoyama, K.; Hiraka, H.; Nakao, H.; Iwasa, K.; Murakami, Y. Competition of magnetic and quadrupolar order parameters in $\mathrm{HoB}_{4}$. J. Phys. Soc. Jpn. 2008, 77, 044709. [CrossRef] 
45. Kim, J.Y.; Cho, B.K.; Han, S.H. Anisotropic magnetic phase diagrams of $\mathrm{HoB}_{4}$ single crystal. J. Appl. Phys. 2009, 105, 07E116. [CrossRef]

46. Heiba, Z.; Schäfer, W.; Jansen, E.; Will, G. Low-temperature structural phase transitions of TbB and ErB $_{4}$ studied by high resolution X-ray diffraction and profile analysis. J. Phys. Chem. Solids 1986, 47, 651-658. [CrossRef]

47. Okada, S.; Kudou, K.; Yu, Y.; Lundström, T. Growth conditions and some properties of $\mathrm{TmB}_{4}$ and $\mathrm{TmAlB}_{4}$ single crystals obtained from high-temperature aluminium metal solution. Jpn. J. Appl. Phys. 1994, 33, 2663-2666. [CrossRef]

Sample Availability: Crystal samples of the $\mathrm{RB}_{4}$ compounds are available from the authors.

(C) 2019 by the authors. Licensee MDPI, Basel, Switzerland. This article is an open access article distributed under the terms and conditions of the Creative Commons Attribution (CC BY) license (http:/ / creativecommons.org/licenses/by/4.0/). 